\title{
Model Application for Sustainable Agricultural Water Use
}

\author{
Jaehak Jeong ${ }^{1, *}$ and Xuesong Zhang ${ }^{2,3}$ \\ 1 Blackland Research Center, Texas A\&M AgriLife Research, Temple, TX 76502, USA \\ 2 Joint Global Change Research Institute, Pacific Northwest National Laboratory and University of Maryland, \\ College Park, MD 20740, USA; xuesong.zhang@pnnl.gov \\ 3 Earth System Science Interdisciplinary Center, University of Maryland, College Park, 5825 University \\ Research Ct, College Park, MD 20740, USA \\ * Correspondence: jeongj@tamu.edu; Tel.: +1-254-774-6000
}

Received: 26 February 2020; Accepted: 3 March 2020; Published: 14 March 2020

\begin{abstract}
With the growing population and climate change, increasing demands for water are intensifying competition between agricultural stakeholders. Since the mid-20th century, numerous crop models and modeling techniques have emerged for the quantitative assessment of cropping systems. This article introduces a collection of articles that explore current research in model applications for sustainable agricultural water use. The collection includes articles from model development to regional and field-scale applications addressing management effects, model uncertainty, irrigation decision support systems, and new methods for simulating salt balances. Further work is needed to integrate data science, modern sensor systems, and remote sensing technologies with the models in order to investigate the sustainability of agricultural systems in regions affected by land-use change and climate change.
\end{abstract}

Keywords: agricultural management; modeling; decision support; sustainable water use

\section{Introduction}

Water is an essential, but limited, resource on Earth which is required to grow crops. The water cycle on cropland is heavily influenced by the global and local climate as well as land management activities. According to the Food and Agriculture Organization of the United Nations (FAO), the world's population is expected to grow to 10 billion by 2050 and significantly boost agricultural demand [1]. The increasing frequency of extreme climatic conditions, combined with agricultural intensification occurring at different speeds, is making it more difficult to sustain agricultural water use [2]. Globally, agricultural water uses represent $70 \%$ of all water withdrawals [3]. To meet the goals of feeding a growing world population while also mitigating the negative environmental effects of agriculture, it is crucial to advance the science and knowledge of soil-water-crop systems in order to provide information for efficient decision making by producers and water managers.

Crop simulation models (CSMs) are often used as research tools to help understand agronomic and (or) environmental processes such as soil water flow, growth dynamics, and $\mathrm{C} / \mathrm{N}$ balances. Process-based CSMs simulate the growth and development of crops using historical (or projected) weather, local soil properties, and management details such as planting/harvesting date, fertilizer/irrigation amounts, and tillage dates. They have been widely adopted by the research community to evaluate the effects of climate change, climatic anomalies, and management decisions upon crop yield and/or environmental effects of cropping practices (e.g., [4-7]).

This article introduces the Model Application for Sustainable Agricultural Water Use Special Issue, published in the Agronomy journal. This special collection includes ten peer-reviewed articles 
that present state-of-the-art model applications and developments to better understand the agronomic and environmental effects of agricultural management, with an emphasis on agricultural water use. The wide-spanning topics covered demonstrate the continuing development and versatility of CSMs, which make them more predictively credible and fill gaps in knowledge and modeling capacity.

\section{Agronomic and Environmental Effects of Agricultural Managements}

CSMs are useful tools for research in understanding the effects of agricultural management. For example, AquaCrop has been found to be a useful tool for predicting the growth of faba bean under various management conditions [8]. Durigon and coauthors [9] found that irrigation deficit has the most pronounced effect on shoot architecture in common bean plants. Zhao and coauthors [10] used the Agricultural Policy Environmental Extender (APEX) model to simulate spring peanut under various irrigation regimes and planting dates. The model successfully replicated the growth and yields and identified the best management scenario based on water use efficiency. When the APEX model was enhanced for estimating salt dynamics in the plant-soil-water system, Goehring and coauthors [11] performed a long-term simulation and reported that growing quinoa-a halophyte-in saline soil may provide more agronomic value (grain and biomass production) than environmental benefits (the removal of salt from soils).

\section{CSMs as a Decision Tool}

López-Ballesteros and coauthors [12] explored the applicability of best management practices (BMPs) to mitigate the water quality effects of non-point source pollution in an ungagged catchment with mixed land uses and distributed sources using the Soil and Water Assessment Tool (SWAT). Results from the SWAT model, which was calibrated using remotely sensed (RS) evapotranspiration data before being implemented for BMP scenario evaluation, demonstrate the efficacy of the tool to inform watershed managers of the potential benefits of various BMP scenarios in reducing sediment yield and N/P loads to streams. Chen and coauthors [13] evaluated a real-time decision support system for irrigation scheduling (DSSIS) which was built with an agro-hydrological model. When applied to a cotton field, the authors found that the DSSIS performed better than other methods that were evaluated concurrently.

Notably, all CSMs and modeling tools published in this Special Issue are open-source to either a full (both the source code and executable are publicly available) or partial (the model executable is public domain but the source code is not freely available) extent. Due to the nature of open-source software, the freedom of modification, reproduction and application of the model/source code allows rapid adaptation by users. In the same context, the work by Camargo Rodriguez and Ober [14] on delivering a $\mathrm{R}$ version of the AquaCrop model through GitHub repo demonstrates the significance of the open-source approach in crop modeling for continuing model development and modification.

\section{Uncertainty Analysis}

Most process-based CSMs require parameterization for robust performance and replicability. Fang and coauthors [15] showed that model uncertainty can be significant if limited types of reference datasets (e.g., spatial or temporal dataset) are used during model parameterization. The authors suggest that model users present outputs with confidence intervals. Equifinality is a term often used in model simulation that indicates a situation where multiple sets of parameters produce similar or acceptable results. Song and coauthors [16] suggest that the issue of equifinality can lead to flawed decisions as a result of substantial uncertainty linked to equifinality.

Author Contributions: Conceptualization, J.J.; investigation, J.J. and X.Z.; writing—original draft preparation, J.J.; writing-review and editing, J.J. and X.Z.; visualization, J.J. All authors have read and agreed to the published version of the manuscript.

Funding: This work was supported in part by the USDA National Institute of Food and Agriculture, Hatch project 1016186. 
Acknowledgments: We thank June Wolfe III for his constructive comments and support on the manuscript.

Conflicts of Interest: The authors declare no conflict of interests.

\section{References}

1. FAO. The Future of Food and Agriculture-Trends and Challenges; Food and Agriculture Organisation Rome: Rome, Italy, 2017; ISBN 978-92-5-109551-5.

2. Kharin, V.V.; Zwiers, F.W.; Zhang, X.; Wehner, M. Changes in temperature and precipitation extremes in the CMIP5 ensemble. Clim. Chang. 2013, 119, 345-357. [CrossRef]

3. FAO. FAOSTAT. Available online: http://faostat.fao.org (accessed on 13 March 2020).

4. Moen, T.N.; Kaiser, H.M.; Riha, S.J. Regional yield estimation using a crop simulation model: Concepts, methods, and validation. Agric. Syst. 1994, 46, 79-92. [CrossRef]

5. Liu, H.; Yang, J.; Drury, C.A.; Reynolds, W.; Tan, C.; Bai, Y.; He, P.; Jin, J.; Hoogenboom, G. Using the DSSAT-CERES-Maize model to simulate crop yield and nitrogen cycling in fields under long-term continuous maize production. Nutr. Cycl. Agroecosyst. 2011, 89, 313-328. [CrossRef]

6. Tan, G.; Shibasaki, R. Global estimation of crop productivity and the impacts of global warming by GIS and EPIC integration. Ecol. Model. 2003, 168, 357-370. [CrossRef]

7. Geerts, S.; Raes, D.; Garcia, M. Using AquaCrop to derive deficit irrigation schedules. Agric. Water Manag. 2010, 98, 213-216. [CrossRef]

8. Zeleke, K.T. AquaCrop Calibration and Validation for Faba Bean (Vicia faba L.) under Different Agronomic Managements. Agronomy 2019, 9, 320. [CrossRef]

9. Durigon, A.; Evers, J.; Metselaar, K.; de Jong van Lier, Q. Water Stress Permanently Alters Shoot Architecture in Common Bean Plants. Agronomy 2019, 9, 160. [CrossRef]

10. Zhao, J.; Chu, Q.; Shang, M.; Meki, M.N.; Norelli, N.; Jiang, Y.; Yang, Y.; Zang, H.; Zeng, Z.; Jeong, J. Agricultural Policy Environmental eXtender (APEX) Simulation of Spring Peanut Management in the North China Plain. Agronomy 2019, 9, 443. [CrossRef]

11. Goehring, N.; Verburg, P.; Saito, L.; Jeong, J.; Meki, M.N. Improving Modeling of Quinoa Growth under Saline Conditions Using the Enhanced Agricultural Policy Environmental eXtender Model. Agronomy 2019, 9, 592. [CrossRef]

12. López-Ballesteros, A.; Senent-Aparicio, J.; Srinivasan, R.; Pérez-Sánchez, J. Assessing the Impact of Best Management Practices in a Highly Anthropogenic and Ungauged Watershed Using the SWAT Model: A Case Study in the El Beal Watershed (Southeast Spain). Agronomy 2019, 9, 576. [CrossRef]

13. Chen, X.; Qi, Z.; Gui, D.; Gu, Z.; Ma, L.; Zeng, F.; Li, L.; Sima, M.W. A Model-Based Real-Time Decision Support System for Irrigation Scheduling to Improve Water Productivity. Agronomy 2019, 9, 686. [CrossRef]

14. Camargo Rodriguez, A.V.; Ober, E.S. AquaCropR: Crop Growth Model for R. Agronomy 2019, 9, 378. [CrossRef]

15. Fang, Q.; Ma, L.; Harmel, R.D.; Yu, Q.; Sima, M.W.; Bartling, P.N.S.; Malone, R.W.; Nolan, B.T.; Doherty, J. Uncertainty of CERES-Maize Calibration under Different Irrigation Strategies Using PEST Optimization Algorithm. Agronomy 2019, 9, 241. [CrossRef]

16. Song, J.-H.; Her, Y.; Jun, S.M.; Hwang, S.; Park, J.; Kang, M.-S. Lessons from Assessing Uncertainty in Agricultural Water Supply Estimation for Sustainable Rice Production. Agronomy 2019, 9, 662. [CrossRef] 